\title{
Molecular Investigation and Phylogenetic Analysis of Anaplasma spp. and Ehrlichia spp. (Based on 16S rRNA gene) Isolated from Hyalomma Ticks in the Border of Iran and Pakistan
}

Nayyereh Choubdar

Tehran University of Medical Sciences

Fateh Karimian

Tehran University of Medical Sciences

Mona Koosha

Tehran University of Medical Sciences

Jalil Nejati

Zahedan University of Medical Sciences

Mohammad Oshaghi ( $\sim$ moshaghi@sina.tums.ac.ir)

Tehran University of Medical Sciences School of Medicine https://orcid.org/0000-0003-3004-0364

\section{Research Article}

Keywords: Anaplasmosis, Ehrlichiose, Hard ticks, Iran, Pakistan, Tick-borne diseases

Posted Date: February 10th, 2021

DOI: https://doi.org/10.21203/rs.3.rs-210989/v1

License: (c) (1) This work is licensed under a Creative Commons Attribution 4.0 International License.

Read Full License 


\section{Abstract}

Background: Anaplasmosis and Ehrlichiosis are tick-borne diseases affecting human beings and livestock in tropical and subtropical regions. Animal husbandry is the main activity of people in the border of Iran and Pakistan, where thousands of cattle cross the borders into the countries weekly.

Methods: PCR-direct sequencing of the 16S rRNA gene was used to determine the prevalence and geographical distribution of the disease agents in Hyalomma hard ticks.

Results: Six Hyalomma species were found in the region, where Hy.anatolicum was the most prevalent species collected on goats, cattle, and camel. Anaplasma / Ehrlichia genomes were found in $68.3 \%$ of the specimens. Anaplasma ovis, A.marginale, and E.ewingii DNA prevalence in the infected ticks were 81.82, 9.09 , and $9.09 \%$ respectively. The DNA sequence and phylogenetic analysis of the $16 S$ rRNA gene confirmed the detection of these three Anaplasmosis agents, showing $99-100 \%$ identity with the strains previously reported in Genbank from different part of the world.

Conclusions: Since A.ovis and A.marginale are considered as important livestock pathogens, and E.ewingii is an important human pathogen, both farmers and people involved in livestock along the border of the two countries need to be made aware of the risks posed by tick infestation and the tickborne disease.

\section{Background}

Ticks (Acari: Ixodidae) are considered to be the second most common vector of human diseases worldwide after mosquitoes [1], but they are the most important vectors of disease-causing pathogens in domestic and wild animals. Ticks transmit a wide variety of pathogens including viruses, bacteria and protozoa to vertebrates.

Genus of Anaplasma Theiler 1910, is an intracellular, Gram-negative bacterium and the representative of the order Rickettsiales classified into Anaplasmataceae family. It is a mix of emerged and emerging tickborne pathogens that cause Anaplasmosis in humans and many mammalian species worldwide particularly in tropical and subtropical regions, including Iran [2]. Several species of Anaplasma have been detected in domestic animals, including A. phagocytophilum Foggie 1949, A.marginale Theiler 1910, A. ovis Lestoquard 1924, A. centrale Theiler 1911, A. bovis Donatien and Lestoquard 1936, and A. platys Dumler et al. 2001. Anaplasma species are found in a broad range of wild and domestic mammals. Ehrlichiosis, caused by Ehrlichia spp., and transmitted by ticks, is another tick-borne disease closely related to Anaplasmosis [3]. Some species of Ehrlichia have been identified as pathogens in humans. For example, Ehrlichia (E.) chaffeensis causes human monocytic ehrlichiosis, E. equi, E. ewingii, and $E$. phagocytophila causes human granulocytic ehrlichiosis, E. sennetsu causes a mononucleosis-like illness, and $E$. canis causes asymptomatic infection. The zoonotic nature of the human Ehrlichioses is supported by reports of natural infections with the same Ehrlichia species in dogs, deer, horses, and rodents [4]. 
Iran has various climates and each one may harbour several different tick species, which is responsible for the difference in the epidemiology of Anaplasmosis/Ehrlichiosis in different regions. The Sistan and Baluchistan province in the southeast corner of Iran has a long border with Pakistan and Afghanistan where infectious diseases do not respect international boundaries. Animal husbandry is one of the main activities of people in the province. Every week thousands of livestock including sheep, goats, cows, and buffaloes cross the borders into the countries. It is suggested about one million animals are traded or trafficked yearly to Iran [5].

Nested polymerase chain reaction (PCR) has been displayed to be a highly sensitive and specific test for the diagnosis of Anaplasmosis/Ehrlichiosis [6]. Among different markers, the 16S rRNA gene is one of the common markers used for bacterial genotyping [3].

Despite the identification of Anaplasma/Ehrlichia species in livestock based on the molecular assays, less study has been performed in their vectors. There have been only a few studies on the detection of tick Anaplasmosis/Ehrlichiosis infections in Iran, which reported Anaplasma/Ehrlichia infection in ticks in the north and other parts of Iran [7-9].

Ixodid ticks play an important role in maintaining Anaplasma/Ehrlichia species in nature. It has been reported that Ixodes Latreille, 1795, Rhipicephalus Koch, 1844, Dermacentor Koch, 1844, and Amblyomma Koch, 1844 genera are the main vectors of Anaplasma/ Ehrlichia bacteria in different regions of the world [10]. Although it was reported that Hyalomma ticks are proven vectors of A. marginale [11], Hyalomma spp., are known as the main vector of Crimean-Congo hemorrhagic fever [12] and there is little research on the anaplasmosis/ehrlichiosis and Hyalomma spp., and whether they are the probable vectors of Anaplasma/Ehrlichia spp., is still unproven, thus necessitating this study. In this study, we identified six different Hyalomma species of tick infesting on various domestic animals and further investigated Anaplasma/Ehrlichia infection status in Hyalomma ticks from Sistan and Baluchistan of Iran.

\section{Methods}

\section{Sample collection and tick identification}

The regions investigated include three districts of Sib \& Suran County (Hiduj district) with the geographical coordinates $27^{\circ} 00^{\prime} 02^{\prime \prime} \mathrm{N} 62^{\circ} 07^{\prime} 01^{\prime \prime E}$, Sarbaz County (Pishin district) with the geographical coordinates $30^{\circ} 35^{\prime} 5.31 \mathrm{~N} 66^{\circ} 59^{\prime} 41.19^{\prime \prime} \mathrm{E}$ and Chabahar County (Negour district) with the geographical coordinates $25^{\circ} 23^{\prime} 20.84^{\prime \prime} \mathrm{N} 61^{\circ} 8^{\prime} 18.96^{\prime \prime} \mathrm{E}$, which are located in the southeast of Iran border Pakistan (Fig. 1). The collection of ticks was performed in three randomly selected major husbandry farms in each district between November 2017 and late March 2018 when adult ticks are most active in the region. Totally, 1020 samples were randomly collected from goats, sheep, cattle, and camels. Tick collection was arbitrarily conducted based on the availability of domestic animals for 15 minutes per animal, but efforts were made to obtain a widespread representative sample within the different animal species included in the study. All ticks were transferred to vials and labelled according to their geographical origin and the 
animals from which they were obtained. The collected ticks were subsequently transferred to the Entomology Laboratory in the School of Public Health at the Tehran University of Medical Sciences and were identified to species level based on morphological characteristics and the method of Estrada-Pena [13].

\section{Dna Extraction}

After species identification, the ticks were sterilized by immersion in $70 \%$ alcohol and washed in distilled water and dried on filter paper in a laminar-flow hood then stored at $-80^{\circ} \mathrm{C}$ until the DNA extraction. The DNA extraction was done using the G-spin Genomic DNA Extraction Kit (iNtRON Biotechnology, South Korea) and carried out according to the manufacturer instructions by grinding individual ticks in an Eppendorf microtube after isolated tick incubation in the liquid nitrogen tank. Afterward, the extracted DNA was suspended in sterile distilled water and was then stored at $-20^{\circ} \mathrm{C}$ prior to molecular investigation.

\section{Molecular detection of Anaplasma /Ehrlichia spp.,}

In this study, we followed the method of Li et al [14] to differentiate species of Anaplasma genera based upon genetic analyses of $16 S$ rRNA. The Anaplasma/Ehrlichia spp., 16S rRNA gene was amplified using the nested PCR protocol and the species-specific primers already designed by Rar et al [15]. The forward and reverse primers for outer reactions were Ehr1 (5' -GAA CGAA CGC TGG CGG CAA GC-3') and Ehr2 (5'AGT A(T/C)C G(A/G)A CCA GAT AGC CGC-5') and for inner reactions were Ehr3 (5'- TGC ATA GGA ATC TAC CTA GTA G- $3^{\prime}$ ) and Ehr4 (5'- CTA GGA ATT CCG CTA TCC TCT- 3'). PCR reactions were performed in $25 \mu \mathrm{L}$ reaction mixture containing $12.5 \mu \mathrm{L}$ of the Hot Start Taq $2 X$ Master Mix, $1 \mu \mathrm{L}$ of each of the forward and reverse primers, $2 \mu \mathrm{L}$ of DNA template and $7.5 \mu \mathrm{L}$ of nuclease-free $\mathrm{H}_{2} \mathrm{O}$ to bring the volume to $25 \mu \mathrm{L}$. PCR reactions were performed in a DNA thermocycler (Eppendorf, Germany) and PCR condition was done to $15 \mathrm{~min}$ at $95^{\circ} \mathrm{C}$ for initial denaturation step, $60 \mathrm{~s}$ at $94^{\circ} \mathrm{C}$ in each cycle for denaturing step, $60 \mathrm{~s}$ at $57^{\circ} \mathrm{C}$ for annealing and $60 \mathrm{~s}$ at $72^{\circ} \mathrm{C}$ for extension step followed by 35 cycles and then a final extension for $10 \mathrm{~min}$ at $72^{\circ} \mathrm{C}$. $2 \mu \mathrm{L}$ of the products of the first round of PCR was used as the template for the second round of PCR, which was carried out under the same conditions and reaction mixture as the first round except that were used as the primers [15].

To assess the presence of specific bands for Anaplasma spp., PCR amplification was electrophoresed in $1.5 \%$ agarose gel and the size of each PCR product was estimated using a 100 base pair (bp) ladder run on the same gel as the marker and then visualized under a UV transilluminator. Two negative controls including double distilled water and DNA template of non-infected tick and positive control (Anaplasma DNA) were included in each PCR assay.

\section{Dna Sequencing And Phylogenetic Analysis}


The positive PCR products were purified and bidirectional DNA sequencing was performed using the same inner PCR primers used for nested PCR amplification. The acquired sequences in this study were edited and assembled using Chromas and Bioedit software to construct consensus sequences and analysed using blast in NCBI (Nucleotide collection) database (https://www.ncbi.nlm.nih.gov/). The consensuses of confident sequences were aligned with other Anaplasma corresponding sequences available in Genbank using multiple-sequence alignments available in CLUSTAL Omega (https://www.ebi.ac.uk/Tools/msa/clustalo). Also, available gene sequences of Ehrlichia ewingii, and Spiroplasma sp., as outgroup, were obtained from Gen bank and combined with the Anaplasm sequences for phylogenetic analysis. All DNA sequences used for alignment were cut to get a consistent region (470 bp). Phylogenetic and molecular evolutionary analyses were conducted with MEGA 7 software [16]. For phylogenetic analysis, three representative sequences of $A$. ovis, one representative sequence of A.marginale, and one representative sequence of $E$. ewingii, obtained from this study were combined with a subset of available representative sequences of all Anaplasma spp., and E. ewingii. Details of the sequences used for this study have been shown in Table 1. The data were aligned and the Maximum likelihood method was employed to construct a phylogenetic tree. The same program was utilized to evaluate the stability of the obtained tree through bootstrap analysis with 1000 replicates. 
Table 1

Details of the bacterial species used for phylogenetic analysis in this study.

\begin{tabular}{|c|c|c|c|}
\hline Bacterial species & Origin & $\begin{array}{l}\text { Gen bank } \\
\text { ID number }\end{array}$ & References \\
\hline \multirow[t]{16}{*}{ A. bovis } & China & MG869525 & [35] \\
\hline & Russia & KC484563 & Direct submission \\
\hline & Iran-East Azarbaijan & MH538097 & Direct submission \\
\hline & $\begin{array}{l}\text { Iran-Borderline of Iran- } \\
\text { Afghanistan }\end{array}$ & KM056396 & Direct submission \\
\hline & 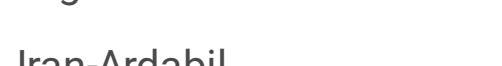 & KF766097 & [23] \\
\hline & Iran-North Khoracan & KM517580 & Direct submission \\
\hline & Iran-Mazandaran & JF514506 & [7] \\
\hline & 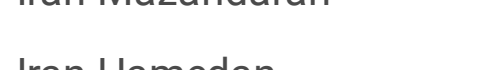 & MF979832 & Direct submission \\
\hline & (1) & MF979850 & Direct submission \\
\hline & Ahmad & MG018481 & Direct submission \\
\hline & Iran-Saveh & KX760106 & Direct submission \\
\hline & Iran-Golestan & MK310475 & This study \\
\hline & Iran-Sarbaz & MK310472 & This study \\
\hline & Iran-Sib and Suran & MH480603 & This study \\
\hline & Iran- Chabahar & MK310471 & This study \\
\hline & Iran- Chabahar & & \\
\hline A. bovis & Iran-Mazandaran & KP017262 & Direct submission \\
\hline \multirow[t]{8}{*}{ A. marginale } & Australia & AF414874.1 & [36] \\
\hline & Iran-Sarbaz & MK310488 & This study \\
\hline & Iran-Zabol & MK016525 & Direct submission \\
\hline & Iran-Khozestan & MG757665 & Direct submission \\
\hline & Brazil & СР023731 & Direct submission \\
\hline & China & MF289480 & Direct submission \\
\hline & Thiland & KT264188 & Direct submission \\
\hline & Uganda & KU686794 & Direct submission \\
\hline A. platys & Iran-Zabol & MK016523 & Direct submission \\
\hline
\end{tabular}




\begin{tabular}{|llll|}
\hline Bacterial species & Origin & $\begin{array}{l}\text { Gen bank } \\
\text { ID number }\end{array}$ & References \\
\hline A. phagocytophilum & South Korea & MF787270 & Direct submission \\
\hline A. odocoilei & USA & KT870132 & Direct submission \\
\hline A. centrale & Iran-Mazandaran & JF514509 & Direct submission \\
& Japan & AB588977 & Direct submission \\
\hline A. capra [14] & China & KY242456 & Direct submission \\
\hline E. ewingii & Iran-Sib and Suran USA & MK310490 & This study \\
& Tajikistan & U96436 & [37] \\
& China & KM995821 & Direct submission Direct \\
& & MH879869 & submission \\
\hline $\begin{array}{l}\text { Spiroplasma } \\
\text { chrysopicola [38] }\end{array}$ & USA & AY189127 & [39] \\
\hline
\end{tabular}

\section{Results}

\section{Ticks species and abundance}

Hard tick specimens were collected in rural areas of Chabahar, Sarbaz and Sib \& Suran districts situated in the southeast of Iran and were tested for the presence of Anaplasma by screening nested PCR assays with specific primers against the $16 S$ rRNA gene of the bacteria. A total of 1020 Hyalomma ticks were collected in the study areas where $H y$. anatolicum was the most prevalent species in all three districts. These ticks belonged to six species including Hy. anatolicum Koch, 1844 ( $n=462,228$ from cattle and 234 from goat), Hy. asiaticum Schulze \& Schlottke, 1930 ( $n=143,87$ from camel, 25 from goat, and 31 from cattle), Hy. marginatum Koch, 1844 ( $n=203,134$ from cattle, 66 from goat and 3 from camel), Hy. dromedarii Koch, 1844 ( $n=188,46$ from goat and 142 from camel), Hy. schulzei Olenev, 1931 ( $n=17,17$ from goat), and Hy. detricum Schulze, 1919 ( $n=6,6$ from camel) (Table 2). 
Table 2

Details of tick specimens collected from animals in the study area.

\begin{tabular}{|c|c|c|c|c|c|c|}
\hline \multirow[t]{2}{*}{ Location } & \multirow[t]{2}{*}{ Tick species } & \multicolumn{3}{|c|}{ No of ticks on animal } & \multirow[t]{2}{*}{ Subtotal } & \multirow[t]{2}{*}{ Total } \\
\hline & & Cattle & Goat & Camel & & \\
\hline \multirow[t]{3}{*}{ Chabahar } & Hy.marginatum & 41 & 36 & 0 & 77 & 312 \\
\hline & Hy.anatolicum & 134 & 59 & 0 & 193 & \\
\hline & Hy.asiaticum & 17 & 25 & 0 & 42 & \\
\hline \multirow[t]{4}{*}{ Sarbaz } & Hy.marginatum & 19 & 13 & 0 & 32 & 322 \\
\hline & Hy.anatolicum & 43 & 132 & 0 & 175 & \\
\hline & Hy.dromedarii & 0 & 46 & 52 & 98 & \\
\hline & Hy.schulzei & 0 & 17 & 0 & 17 & \\
\hline \multirow[t]{5}{*}{ Sib and Suran } & Hy.asiaticum & 14 & 0 & 87 & 101 & 386 \\
\hline & H.dromedarii & 0 & 0 & 90 & 90 & \\
\hline & Hy.detricum & 0 & 0 & 6 & 6 & \\
\hline & Hy.marginatum & 75 & 17 & 3 & 95 & \\
\hline & Hy.anatolicum & 51 & 43 & 0 & 94 & \\
\hline Total & & 394 & 388 & 238 & 1020 & 1020 \\
\hline
\end{tabular}

Anaplasma / Ehrlichia infection in ticks

Using broad-spectrum EHR primers, 256 out of 1020 collected ticks (25\%) were tested for the presence of Anaplasma's or related species $16 S$ rRNA gene. The result of PCR assays revealed the presence of Anaplasma/Ehrlichia genomes in 68.3\% (175 out of 256) of the selected specimens. The species, number and prevalence of Anaplasma/Ehrlichia in Hyalomma spp., ticks at each collection site are shown in Table 3. The rate of Anaplasma spp., and E.ewingii infections was similar (67.8\%-69.2\%) in Hy.

anatolicum, Hy. dromedarii, Hy. asiaticum, and Hy. marginatum specimens. This rate, however, was higher in Hy. detricum (2 out of 2, 100\%) and lower in Hy. schulzei (2 out of 5, 40\%) than the other four species. A sub set of positive PCR specimens against AnaplasmalEhrlichia genome in ticks were sequenced and the consensus sequences were deposited in Gen bank. Details of the Anaplasma/Ehrlichia spp., positive samples are listed in Table 4. 
Table 3

Details of Anaplasma / Ehrlichia infection in different Hyalomma species collected from Sistan and Baluchistan Province, southeast corner of Iran, 2016-2017.

\begin{tabular}{|lllll|}
\hline Tick species & $\begin{array}{l}\text { No. of } \\
\text { collected } \\
\text { samples }\end{array}$ & $\begin{array}{l}\text { No. of specimen } \\
\text { tested (\%) }\end{array}$ & $\begin{array}{l}\text { Anaplasma } \\
\text { positive (\%) }\end{array}$ & $\begin{array}{l}\text { No. of specimens } \\
\text { sequenced }\end{array}$ \\
\hline $\begin{array}{l}\text { Hy. } \\
\text { anatolicum }\end{array}$ & 462 & $115(24.1)$ & $78(67.8)$ & 7 \\
\hline $\begin{array}{l}\text { Hy. } \\
\text { asiaticum }\end{array}$ & 143 & $35(24.4)$ & $24(68.5)$ & 3 \\
\hline $\begin{array}{l}\text { Hy. } \\
\text { dromedarii }\end{array}$ & 188 & $47(25)$ & $32(68.1)$ & 4 \\
\hline $\begin{array}{l}\text { Hy. } \\
\text { marginatum }\end{array}$ & 204 & $52(25.4)$ & $36(69.2)$ & 4 \\
\hline $\begin{array}{l}\text { Hy. } \\
\text { detricum }\end{array}$ & 6 & $2(33.3)$ & $2(100)$ & 2 \\
\hline Hy. schulzei & 17 & $5(29.4)$ & $2(40)$ & 2 \\
\hline Total & 1020 & $256(25.1)$ & $175(68.3)$ & 22 \\
\hline
\end{tabular}


Table 4

Details of infected ticks to Anaplasma spp., /Ehrlichia ewingii in three districts of Sistan and Baluchistan Province, southeast corner of Iran, 2016-2017.

\begin{tabular}{|llllll|}
\hline Tick species & Tick sex & Host & Location & Infection & Genbank \\
& & & & & ID number \\
\hline Hy. anatolicum & Female & Cattle & Chabahar & A.ovis & MK310471 \\
\hline Hy. anatolicum & Female & Cattle & Sib and Suran & A.ovis & MK310472 \\
\hline Hy. anatolicum & Female & Cattle & Sib and Suran & A.ovis & MK310473 \\
\hline Hy. anatolicum & Male & Goat & Sib and Suran & A.ovis & MK310474 \\
\hline Hy. anatolicum & Female & Goat & Sarbaz & A.ovis & MK310475 \\
\hline Hy. anatolicum & Female & Goat & Sarbaz & A.ovis & MK310476 \\
\hline Hy. asiaticum & Female & Cattle & Sib and Suran & A.ovis & MK310477 \\
\hline Hy. asiaticum & Male & Goat & Sib and Suran & A.ovis & MK310478 \\
\hline Hy. asiaticum & Female & Cattle & Chabahar & A.ovis & MK310479 \\
\hline Hy.dromedarii & Female & Goat & Sarbaz & A.ovis & MK310480 \\
\hline Hy. dromedarii & Male & Camel & Sarbaz & A.ovis & MK310481 \\
\hline Hy. marginatum & Male & Cattle & Sib and Suran & A.ovis & MK310482 \\
\hline Hy. marginatum & Male & Goat & Chabahar & A.ovis & MK310483 \\
\hline Hy. marginatum & Female & Cattle & Chabahar & A.ovis & MK310484 \\
\hline Hy. detricum & Male & Camel & Sib and Suran & A.ovis & MK310485 \\
\hline Hy. detricum & Male & Camel & Sib and Suran & A.ovis & MK310486 \\
\hline Hy.schulzei & Female & Goat & Sarbaz & A.marginale & MK310487 \\
\hline Hy. schulzei & Male & Goat & Sarbaz & A.marginale & MK310488 \\
\hline Hy. dromedarii & Female & Camel & Sib and Suran & E.ewingii & MK310490 \\
\hline Hy. dromedarii & Male & Camel & Sib and Suran & E.ewingii & MK310491 \\
\hline
\end{tabular}

\section{Sequence And Phylogenetic Analysis}


Analysis of the sequence data showed that $A$. ovis was the most prevalent (18 out of $22,81.82 \%$ ) Anaplasma species in the study area. All of the strains of $A$. ovis isolated in this study were identical to each other and to the other Iranian strains and to the strains from China (Accession number: MG869525) and Russia (Accession number: KC484563). In addition to A. ovis, two A. marginale isolates $(9.09 \%)$ and two E. ewingii isolates (9.09\%) were found in the selected ticks. Sequences of $A$. marginale in this study were identical to their counterparts from USA, Tajikistan, and China. Similarly, the isolated strains of $E$. ewingii obtained in this study were identical with the isolates from Australia, USA, Brazil, Thailand, Iran, China, and Uganda. The sequence similarities between the isolated strains of $A$. marginale and or $E$. ewingii with the available data in Gen bank were more than $99-100 \%$.

The phylogenetic analysis of Anaplasma/ Erhrlichia species was performed using the sequences obtained in this study in combination with the available data retrieved from Genbank. The bacterial species were clustered in four different clades including I) A. ovis, II) A. marginale, III) A. platys-A. phagocytophilum-A. odocoilei, IV) A. centrale-A. capra (Fig. 2). Interestingly, all E. ewingii isolates were associated with the branches of clade III. This analysis showed no clear geographical pattern or further association with host among the A. ovis, An. marginale, or E. ewingii isolates.

\section{Discussion}

This is the first comprehensive study of Hyalomma ticks attached to domestic animals and their associated Anaplasma/ Ehrlichia species conducted on the border of Iran and Pakistan, southeast corner of Iran. The results show that there are six infesting Hyalomma spp., ticks and that there are at least three Anaplasmosis agents that can be transmitted through a tick bite.

These infestations may cause considerable blood losses from livestock and can also transmit severe tick-borne diseases in the region. These diseases impose massive losses on the livestock sector including reducing the production of meat, milk, wool, and skin in the south corner of Iran. Results of this study is generally in accordance with observations on hard ticks and pathogens from animals in Pakistan neighbouring country and other parts of Iran, while there are some distinctive results in this study $[7,17$, 22].

In this study, Hy. anatolicum-infested animals were found to be the most common and have the widest geographical range. This three-host tick species was previously reported as the most prevalent hard tick from different parts of Pakistan including Baluchistan of Pakistan the closest area to Baluchistan of Iran, and most parts of Iran $[7,8,17,18,19,20]$.

The present study provides new information about the risks of high diverse Hyalomma infestation of domestic animals in south-eastern Iran. This situation may address the animal traffic from neighbouring countries, which may lead to more frequent encounters with these tick species. The ticks in this study were feeding on the animals at the time of collection and were, therefore, potentially transmitting any Anaplasma spp., to the animals while feeding. However, the possibility that these ticks play a significant role in Anaplasmosis transmission to domestic animals where it is endemic requires further investigation. 
Hyalomma spp., ticks in this region carried the Anaplasma and Ehrlichia agents, including A. ovis, A. marginale, and E. ewingii. These Anaplasmataceae pathogens were previously detected using molecular methods in hard ticks in several regions in Iran [17, 19, 20,21]. The prevalence of Hyalomma spp., with Ehrlichia / Anaplasma spp., DNA in this study was $68 \%$, which is higher than the rate of infection in the previous reports from other parts of the country. The prevalence of infection was reported as 4.6\% [17], $25 \%$ [22], 43.84\% [23], and 55.5\% [9]. The different results regarding the tick infection rate in the study region could be explained by the different environmental factors, collection time, the sampling method, the tick community structure.

The result of this study and the above literature showed that different species of Hyamlomma could be one of the primary carriers and reservoirs for Anaplasma / Ehrlichia spp., in the country. In addition to Hyalomma spp., ticks, other hard ticks including Rhipicephalous bursa, $R$. sanguineous, Dermacentor marginaus, Haemaphysalis erinacei, Ixodes ricinus $[7,8,17,23]$ are reported as vectors of different tickborne bacteria of the family Anaplasmataceae. However, in other parts of the world, the most important vector of anaplasmosis belongs to different species of Ixodes genus; for example, Ixodes ricinus in Europe, I. persulatus in Eastern Europe and Asia, and I. scapularis in North America [24].

In this study a high prevalence of the anaplasmataceae species $(81.82 \%)$ was of $A$. ovis DNA. This bacterium was isolated from five tick species of $\mathrm{Hy}$. anatolicum (31.8\%), Hy. asiaticum (13.6\%), Hy. marginatum (18.2\%), Hy. dromedarii (0.9\%), and Hy. detricum (0.9\%) which were collected from cattle, goat, and camel. Anaplasma marginale and E. ewingii were found only from $\mathrm{Hy}$. schulzi and $\mathrm{Hy}$. dromedarii collected on goats and camels respectively. Both $A$. ovis and $A$. marginale are important livestock pathogens whereas $E$. ewingii is an important human pathogen. Ehrlichia ewingii mainly infects granulocytes, triggering granulocytic Ehrlichiosis in dog and human [4,34]. Granulocytic Ehrlichiosis in humans has been described in immunosuppressed as well as immunocompetent patients, causing headache, fever, myalgia, vomiting, nausea, acute renal failure, thrombocytopenia, leukopenia and increased liver enzyme activities [25-27]. Anaplasma ovis is less pathogenic than other Anaplasma species, has got worldwide distribution, and is responsible mostly for small ruminant anaplasmosis with a low ranking fever [28, 29]. However, it may be an important disease agent for sheep and goat [30, 31]. Fever, anorexia, fatigue, milk reduction and abortion with a low death rate are the common clinical marks of $A$. ovis in infected animals ${ }^{[32]}$. Anaplasma marginale is known as the most important rickettsia disease in cattle. The common clinical signs of the disease are progressive haemolytic anaemia, decrease milk production, abortions, and death. In addition to cattle, other animals including water buffalo, and wild mammals like deer can be infected [33].

The present study revealed circulation of three species of Anaplasmatacea along the border of Iran and Pakistan. This finding is in agreement with the results of researchers on the border of Iran and Afghanistan as well as Pakistan who reported different tick-borne pathogens including Ehrlichia and Anaplasma in ticks $[8,18]$. In Pakistan, researchers reported $A$. marginale, $A$. centrale, A. ovis, A. platys-like organism, E. minasensis, and two uncharacterized species: Ehrlichia sp., Multan and Anaplasma spp., (BL099-6).

Page $12 / 18$ 
In the current study we did not find A. phagocytophilum or other human granulocytic ehrlichiosis (HGE) agent in the tick specimens. Using more sensitive methods such as real-time PCR (RT-PCR) against ticks or the animal blood of tick hosts might reveal better picture of anaplasmosis agent in the region. Anaplasma phagocytophilum can infect various animals including goats and cows, and can be transmitted to humans by a bite from an infected tick [4].

\section{Conclusions}

In general, farmers and people who are involved in livestock farming along the border of Iran and Pakistan need to be made aware of the risks posed by tick infestation and the tick-borne disease. Pathogens carried by ticks can infect both animals and humans and monitoring of ticks and the pathogens they carry provides insight into the occurrence and spread of zoonotic diseases. Veterinarians in the region should keep these risks in mind and educate people regarding the risks as well as developing optimal approaches for tick protection protocols that maximize people's agreement.

\section{Declarations}

\section{Acknowledgements}

The authors are grateful to thank Farough Askani for his assistance in the field.

Funding: This work has supported by Tehran University of Medical Sciences, Iran, grant number 29005.

\section{Authors' contributions}

NC performed the whole study and writing the manuscript, FK accomplished phylogenetic analysis, MK helped in molecular analysis of data, JN was a major contribution in designing and sample collection, and MAO was the guarantor and analysed and interpreted the data, was the major contributor in the editing of the manuscript. All authors read and approved the final manuscript.

\section{Availability of data and materials}

All data generated or analysed during this study are included in this published article. The sequence data are available at NCBI database.

\section{Ethics approval and consent to participate}

All procedures were performed in accordance with the terms of the Iran Animals (Scientific Procedures) Act Project License and were approved by the Tehran University of Medical Sciences Ethical Review Committee, reference number: IR.TUMS.SPH.REC.1395.926. Due to social concerns, consent to participate was obtained verbally from the owners of the animals used in this study which was approved by the committee. 


\section{Consent for publication}

"Not applicable"

\section{Competing interests}

The authors declare that they have no competing interests with the publication of the manuscript or an institution or product that is mentioned in the manuscript and/or is important to the outcome of the study presented. Authors also disclose conflict of interest with products that compete with those mentioned in their manuscript.

\section{References}

1. De la Fuente J, Estrada-Pena A, Venzal JM, Kocan KM, Sonenshine DE. Overview: ticks as vectors of pathogens that cause disease in humans and animals. Front Biosci. 2008;13:6938-46.

2. Ranjbar-Bahadori S, Eckert B, Omidian Z, Sadr Shirazi N, Parviz S. Babesia ovis as the main causative agent of sheep babesiosis in Iran. J Parasitol Res. 2012;110:1531-36.

3. Ismail N, Bloch KC, McBride JW. Human ehrlichiosis and anaplasmosis. J Clin Lab Med. 2010;30:261-92.

4. Sainz Á, Roura X, Miró G, Estrada-Peña A, Kohn B, Harrus S, Solano-Gallego L. Guideline for veterinary practitioners on canine ehrlichiosis and anaplasmosis in Europe. Parasites Vectors. 2015;8:75.

5. Nematiniya A. Geocultural Inter-relations of Iranian and Pakistani Balochistan in the Globalization Era. J Subcontinent Res. 2013;15:135-52.

6. Ramos CA, Ramos RA, Araújo FR, Guedes Jr, Souza IF, Ono TM, et al. Comparison of nested-PCR with blood smear examination in detection of Ehrlichia canis and Anaplasma platys in dogs. Rev Bras Parasitol Vet. 2009;18:58-62.

7. Hosseini-Vasoukolaei N, Oshaghi MA, Shayan P, Vatandoost H, Babamahmoudi F, Yaghoobi-Ershadi MR, et al. Anaplasma infection in ticks, livestock and human in Ghaemshahr, Mazandaran Province, Iran. J Arthropod Borne Dis. 2014;8:204-11.

8. Jafarbekloo A, Bakhshi H, Faghihi F, Telmadarraiy Z, Khazeni A, Oshaghi MA, et al. Molecular detection of Anaplasma and Ehrlichia infection in ticks in borderline of Iran-Afghanistan. Vector Borne Zoonotic Dis. 2014;7:919-26.

9. Tajedin L, Bakhshi H, Faghihi F, Telmadarraiy Z. High infection of Anaplasma and Ehrlichia spp. among tick species collected from different geographical locations of Iran. Asian Pac J Trop Dis. 2016;6:787-92.

10. Rar V, Golovljova L. Anaplasma, Ehrlichia, and "Candidatus Neoehrlichia" bacteria: pathogenicity, biodiversity, and molecular genetic characteristics, a review. Infect Genet Evol. 2011;11:1842-61. 
11. Shkap V, Kocan K, Molad T, Mazuz M, Leibovich B, Krigel Y, et al. Experimental transmission of field Anaplasma marginale and the A. centrale vaccine strain by Hyalomma excavatum, Rhipicephalus sanguineus and Rhipicephalus (Boophilus) annulatus ticks. Vet Microbiol. 2009;134(3-4): $254-60$.

12. Choubdar N, Oshaghi MA, Rafinejad J, Pourmand MR, Maleki-Ravasan N, Salehi-Vaziri M, et al. Effect of Meteorological Factors on Hyalomma Species Composition and Their Host Preference, Seasonal Prevalence and Infection Status to Crimean-Congo Haemorrhagic Fever in Iran. J Arthropod Borne Dis. 2019;13(3):268-83.

13. Estrada-Pena A, Bouattour A, Camicas J, Walker AR. Ticks of domestic animals in the Mediterranean region. Zaragoza: University of Zaragoza; 2004.

14. Li H, Zheng Y-C, Ma L, Jia N, Jiang BG, Jiang RR, et al. Human infection with a novel tick-borne Anaplasma species in China: a surveillance study. Lancet Infect Dis. 2015;15(6):663-7.

15. Rar VA, Livanova NN, Panov VV, Kozlova IV, Pukhovskaya MN, Vysochina NP, et al. Prevalence of Anaplasma and Ehrlichia species in Ixodes persulcatus ticks and small mammals from different regions of the Asian part of Russia. Int J Med Microbiol. 2008;298:222-30.

16. Kumar S, Stecher G, Tamura K. MEGA7: Molecular Evolutionary Genetics Analysis version 7.0 for bigger datasets. Mol Biol Evol. 2016;33:1870-4.

17. Jafar Bekloo A, Ramzgouyan MR, Shirian S, Faghihi F, Bakhshi H, Naseri F, et al. Molecular characterization and phylogenetic analysis of Anaplasma spp. and Ehrlichia spp., isolated from various ticks in southeastern and northwestern regions of Iran. Vector Borne Zoonotic Dis. 2018;18: $252-57$.

18. Biglari P, Bakhshi H, Chinikar S, Belqeiszadeh H, Ghaffari M, Javaherizadeh S, et al. Hyalomma anatolicum as the main infesting tick in an important livestock rearing region, central area of iran. Iran J Public Health. 2018;47:742-9.

19. Rehman A, Conraths FJ, Sauter-Louis C, Krücken J, Nijhof AM. Epidemiology of tick-borne pathogens in the semi-arid and the arid agro-ecological zones of Punjab province, Pakistan. Transbound Emerg Dis. 2019;66:526-36.

20. Davari B, Alam FN, Nasirian H, Nazari M, Abdigoudarzi M, Salehzadeh A. Seasonal distribution and faunistic of ticks in the Alashtar county (Lorestan Province), Iran. Pan Afr Med J. 2017;27:284-99.

21. Spitalska E, Namavari MM, Hosseini MH, Shad-Del F, Amrabadi OR, Sparagano OA. Molecular surveillance of tick-borne diseases in Iranian small ruminants. Small Ruminant Res. 2005;57:24548.

22. Bekloo AJ, Bakhshi H, Soufizadeh A, Sedaghat MM, Bekloo RJ, Ramzgouyan MR, et al. Ticks circulate Anaplasma, Ehrlichia, Babesia and Theileria parasites in North of Iran. Vet Parasitol. 2017;248:21-4.

23. Khazeni A, Telmadarraiy Z, Oshaghi MA, Mohebali M, Zarei Z, Abtahi SM. Molecular detection of Ehrlichia canis in ticks population collected on dogs in Meshkin-Shahr, Ardebil province, Iran. J Biomed Sci Eng. 2013;6:1-5. 
24. Angelakis E. Rickettsia and rickettsia-like organisms. Fourth Edition. Infectious Diseases.. 2017; 1666-75.

25. Harris RM, Couturier BA, Sample SC, Coulter KS, Casey KK, Schlaberg R. Expanded geographic distribution and clinical characteristics of Ehrlichia ewingii infections, United States. Emerg Infect Dis. 2016;22:862-65.

26. Heitman KN, Dahlgren FS, Drexler NA, Massung RF, Behravesh CB. Increasing incidence of ehrlichiosis in the United States: a summary of national surveillance of Ehrlichia chaffeensis and Ehrlichia ewingii infections in the United States, 2008-2012. Am J Trop Med Hyg. 2016;94:52-60.

27. Regunath H, Rojas-Moreno C, Olano JP, Hammer RD, Salzer W. Early diagnosis of Ehrlichia ewingii infection in a lung transplant recipient by peripheral blood smear. Transpl Infect Dis. 2017;19:e12652.

28. Cabezas-Cruz A, Gallois M, Fontugne M, Allain E, Denoual M, Moutailler S, et al. Epidemiology and genetic diversity of Anaplasma ovis in goats in Corsica, France. Parasit Vectors. 2019;12:3-14.

29. Kuttler KL. Anaplasma infections in wild and domestic ruminants: a review. J Wildl Dis. 1984;20:1220.

30. Rymaszewska A, Grenda S. Bacteria of the genus Anaplasma-characteristics of Anaplasma and their vectors: a review. J Vet Med. 2008;53:573-84.

31. Yasini S, Khaki Z, Rahbari S, Kazemi B, Amoli JS, Gharabaghi A, et al. Hematologic and clinical aspects of experimental ovine anaplasmosis caused by Anaplasma ovis in Iran. Iran J Parasitol. 2012;7:91-8.

32. Stuen S, Longbottom D. Treatment and control of chlamydial and rickettsial infections in sheep and goats. Vet Clin North Am Food Anim Pract. 2011;27:213-33.

33. Aubry P, Geale DW. A review of bovine anaplasmosis. Transbound Emerg Dis. 2011;58:1-30.

34. Motaghipisheh S, Akhtardanesh B, Ghanbarpour R, Aflatoonian MR, Khalili M, Nourollahifard SR, et al. Ehrlichiosis in household dogs and parasitized ticks in Kerman-Iran: preliminary zoonotic risk assessment. J Arthropod Borne Dis. 2016;10:245-51.

35. Guo W-P, Huang B, Zhao Q, Xu G, Liu B, Wang YH, et al. Human-pathogenic Anaplasma spp., and Rickettsia spp., in animals in Xi'an, China. PLoS Negl Trop Dis. 2018;12: e0006916.

36. Hammac GK, Pierlé SA, Cheng X, Scoles GA, Brayton KA. Global transcriptional analysis reveals surface remodeling of Anaplasma marginale in the tick vector. Parasit Vectors. 2014;7:193.

37. Goldman EE, Breitschwerdt EB, Grindem CB, Hegarty BC, Walls JJ, Dumler JS. Granulocytic ehrlichiosis in dogs from North Carolina and Virginia. J vet intern med. 1998;12:61-70.

38. Whitcomb RF, French FE, Tully JG, Gasparich GE, Rose DL, Carle P, et al. Spiroplasma chrysopicola sp. nov., Spiroplasma gladiatoris sp. nov., Spiroplasma helicoides sp. nov., and Spiroplasma tabanidicola sp. nov., from Tabanid (Diptera: Tabanidae) Flies. Int J Syst Evol Microbiol. 1997;47: 713-719. 
39. Gasparich GE, Whitcomb RF, Dodge D, French FE, Glass J, Williamson DL. The genus Spiroplasma and its non-helical descendants: phylogenetic classification, correlation with phenotype and roots of the Mycoplasma mycoides clade. Int J Syst Evol Microbiol. 2004;54:893-918.

\section{Figures}

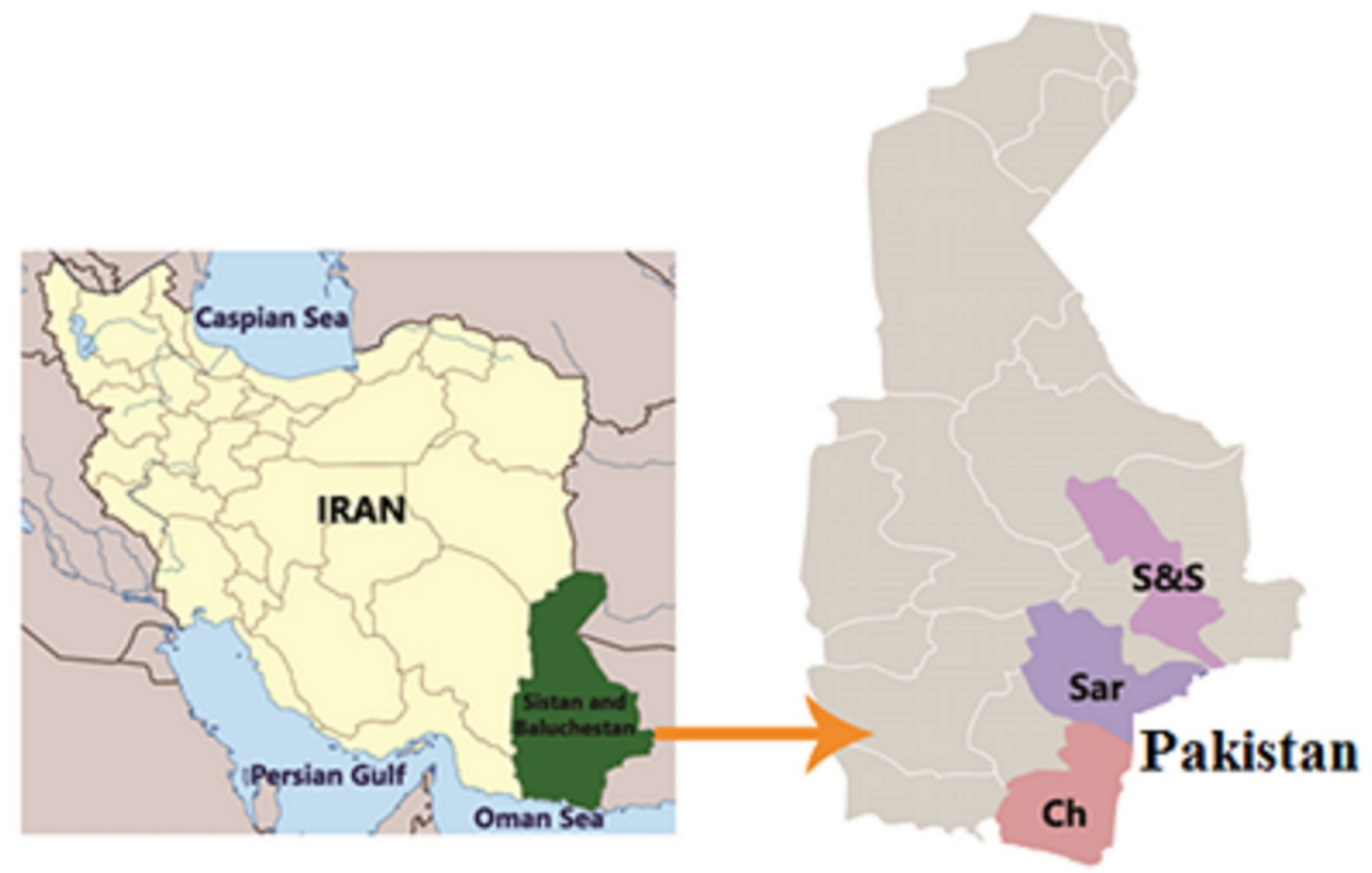

Figure 1

Map showing the locations where ticks were collected in Sistan and Baluchistan. Ch: Chabahar, Sar: Sarbaz, S \& S: Sib and Suran. Note: The designations employed and the presentation of the material on this map do not imply the expression of any opinion whatsoever on the part of Research Square concerning the legal status of any country, territory, city or area or of its authorities, or concerning the delimitation of its frontiers or boundaries. This map has been provided by the authors. 


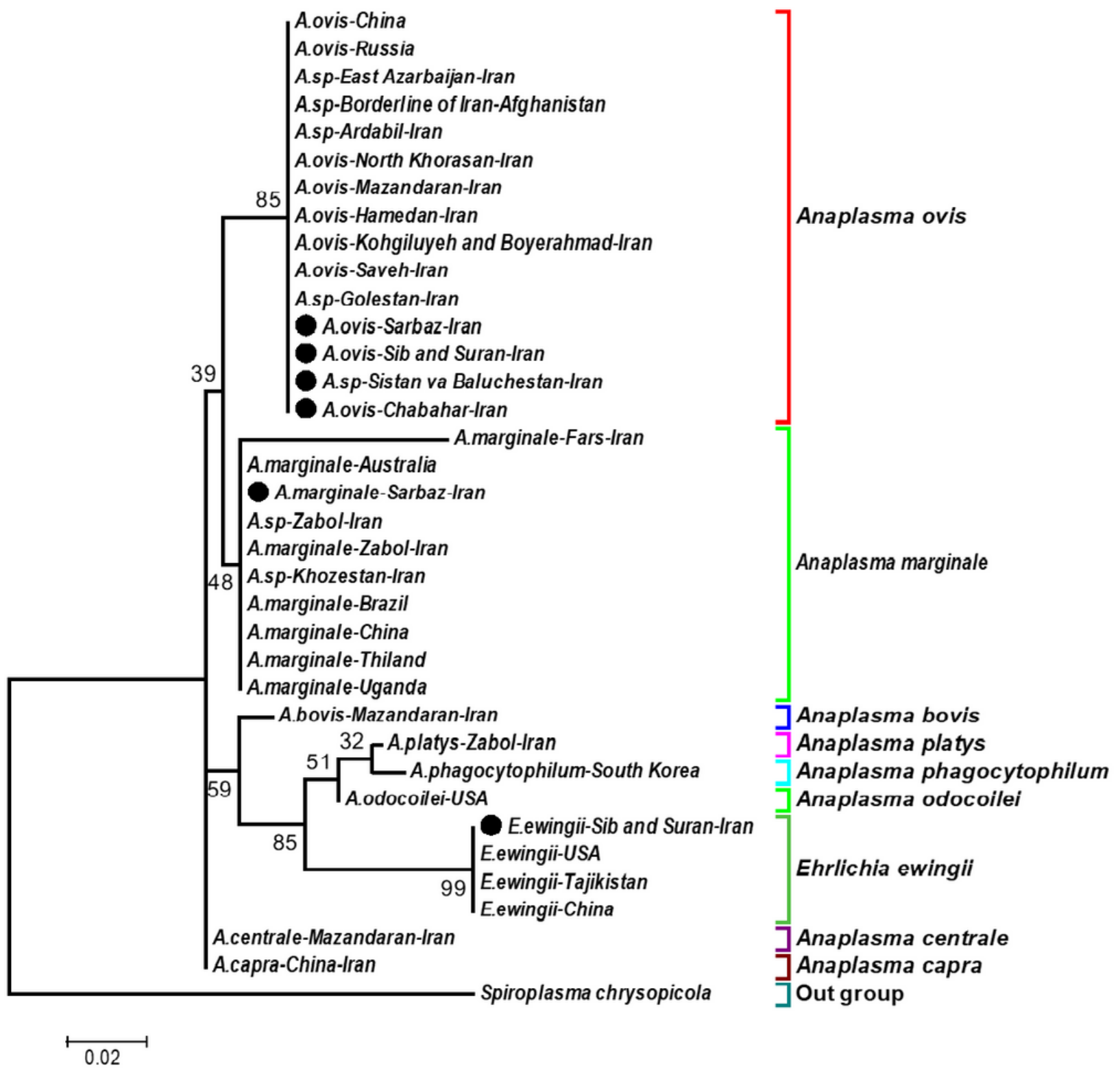

Figure 2

Phylogenetic relationships inferred from 470 bp of 16S rRNA genes of Anaplasma/Ehrlichia species detected in this study and other available data in Genbank. The representative sequences obtained in this study are marked with black circles. The tree was computed by maximum likelihood (MEGA7.0 software). Bootstrap values are shown on nodes.

\section{Supplementary Files}

This is a list of supplementary files associated with this preprint. Click to download.

- graphicalabstract.png 